\title{
Dutch nutrition and care professionals' experiences with undernutrition awareness, monitoring, and treatment among community-dwelling older adults: a qualitative study
}

\author{
Canan Ziylan ${ }^{1,2^{*}}$ (D), Annemien Haveman-Nies², Ellen J. I. van Dongen², Stefanie Kremer ${ }^{1}$ \\ and Lisette C. P. G. M. de Groot ${ }^{2}$
}

\begin{abstract}
Background: Undernutrition can negatively affect community-dwelling older adults' health and quality of life. Undernutrition management guidelines have been developed in the Netherlands for the primary care setting, however, the application of these guidelines remain unsatisfactory. The current study therefore aims to explore qualitatively the experiences of Dutch nutrition and care professionals and researchers with undernutrition awareness, monitoring, and treatment among community-dwelling older adults.

Methods: We telephonically interviewed 22 Dutch nutrition and care professionals and researchers. Our semi-structured interview guide elicited answers that we audiotaped and transcribed verbatim. The interviews were coded using grounded theory and content analysis with the qualitative analysis software MAXQDA, after which the codes were categorized into themes.

Results: The interviews resulted in six themes relevant to the topics of interest: undernutrition awareness, monitoring, and treatment. These were: (1) adverse changes in nutrition behaviour; (2) limited undernutrition awareness; (3) unclear monitoring responsibilities and procedures; (4) lack of awareness, time, and priority as monitoring barriers; (5) lack of treatment personalization and justification; (6) lack of timely treatment implementation and evaluation.

Conclusions: The experts' experiences imply that undernutrition awareness is limited, among both older adults and care professionals. In addition, the interviewees are unclear about which professionals are responsible for monitoring and which monitoring procedures are preferred. The dietitians feel that they become involved too late, leading to decreased treatment effectiveness. In general, the interviewees desire a coherent and feasible allocation of responsibilities regarding undernutrition monitoring and treatment. This implies that the available guidelines on undernutrition management require more attention and facilitation.
\end{abstract}

Keywords: Undernutrition, Community-dwelling older adults, Primary care, Expert interviews

\footnotetext{
* Correspondence: canan.ziylan@wur.nl

${ }^{1}$ Consumer Science \& Health, Wageningen UR Food \& Biobased Research,

P.O. Box 17, 6700 AA Wageningen, The Netherlands

2Division of Human Nutrition, Wageningen University, P.O. Box 8129, 6700 EV

Wageningen, The Netherlands
} 


\section{Background}

Undernutrition can negatively affect community-dwelling older adults' health and quality of life [1] and can be caused by a variety of risk factors such as burden of diseases [2], chewing and swallowing problems [3], alterations in taste sensibility and appetite [4], loneliness [5], and difficulties with meal preparation and food shopping [6]. For many older adults, these risk factors are out their control and enter their lives gradually, often without their noticing and counteracting them. In the Netherlands, the steadily increasing undernutrition in older adults resulted in a prevalence of between 11 and $35 \%$ among Dutch community-dwelling older adults in 2012 [7]. To manage undernutrition successfully, adequate undernutrition monitoring and treatment are imperative. Therefore, in 2011, undernutrition management guidelines have been developed in the Netherlands for the primary and secondary care setting [8].

In the undernutrition management guidelines, the Dutch Malnutrition Steering Group addresses the essential steps regarding undernutrition monitoring and treatment for different care settings. By widely disseminating these guidelines throughout public health organizations, they aimed to achieve the necessary levels of awareness regarding undernutrition management. However, although progress is seen since 2011, both the application of the monitoring guidelines and the results of the provided treatments remain unsatisfactory [9]. According to this article, this dissatisfaction is probably caused by impeding factors such as a lack of priority among general practitioners and limited undernutrition knowledge among dietitians. However, to date, no study has qualitatively explored the reasons for the inadequate undernutrition management in the Dutch primary care setting yet. Conversely, an Australian study that addressed this topic found an explanation in reasons like limited time, priority, and patient willingness [10]. In addition, although more focused on nutrition in general, a Canadian study found similar barriers in primary care, with family physicians reporting 'their formal nutrition training in medical school to be inadequate' [11]. Nonetheless, these reasons seem to explain only part of the problem and can vary with each country and its healthcare system.

In view of the aforementioned difficulties in the Netherlands, we need more insight into the current application of the undernutrition management guidelines. These guidelines describe that to treat undernourished older adults successfully, it is necessary that these older adults are monitored regularly, which is not possible without firstly being aware of undernutrition among older adults. Using these three pillars of undernutrition management as a starting point, we hypothesised that the difficulties in following the guidelines start at undernutrition awareness, with a continuing negative effect on monitoring and treatment. The current study therefore aims to explore qualitatively the experiences of Dutch nutrition and care professionals and researchers with undernutrition awareness, monitoring, and treatment among community-dwelling older adults.

\section{Methods \\ Methodological approach}

The applied methodological approach of this study was a combination of both grounded theory and content analysis. The former manifested itself in the choice to use constant comparative analysis, which meant that data collection and data analysis occurred simultaneously [12]. Regarding the latter, inductive content analysis was applied by using the data directly to define codes and themes [13], which is further explained in the associated analysis section.

\section{Study population}

To reflect the multidisciplinary nature of a successful approach to counteract undernutrition, we applied purposive expert sampling to select a variety of professionals. We explicitly selected groups of professionals with either a direct involvement in the nutrition of older adults or an intensive involvement in their home setting. Consequently, the older adults whom the participants refer to in the interviews were mainly communitydwelling older adults, who nonetheless often suffer from diverse and multiple health concerns. Moreover, we chose participants based on their known involvement with undernutrition management initiatives, such as members of the Dutch Malnutrition Steering Group and researchers. In turn, these experts referred us to other professionals who showed an interest in these experts' activities. All potential participants were contacted by email or telephone and provided with the study's background information. In total, 31 Dutch professionals were contacted, of whom 22 agreed to participate in a telephone interview. The participants included one dietitians' coordinator (DC), five dietitians (Ds), three meal service employees (MSEs), one elder-issues consultant (EC), one informal care consultant (ICC), one geriatric specialist (GS), two general practitioners (GPs), one nurse practitioner (NP), three home care nurses (HCNs), and four researchers involved in nutrition and care research (Rs) (Table 1). Four GPs, three nurse practitioners, and two dietitians declined the interview request because of their self-declared lack of knowledge on undernutrition in older adults.

\section{Data collection}

The telephone interview method was chosen because of its convenience and its ability to be concise yet sufficiently open to assess experiences [14]. The telephone interviews made it possible for the interviewees to talk 
Table 1 Characteristics of the interviewed professionals, grouped by expertise area

\begin{tabular}{|c|c|c|}
\hline Code & Profession & Interview duration (minutes) \\
\hline \multicolumn{3}{|l|}{ Nutrition } \\
\hline DC & Dietitians' coordinator & 37 \\
\hline D1 & Dietitian & 27 \\
\hline D2 & Dietitian & 31 \\
\hline D3 & Dietitian & 43 \\
\hline D4 & Dietitian & 40 \\
\hline D5 & Dietitian & 29 \\
\hline MSE1 & Meal service employee & 38 \\
\hline MSE2 & Meal service employee & 30 \\
\hline MSE3 & Meal service employee & 34 \\
\hline \multicolumn{3}{|l|}{ Care } \\
\hline EC & Elder-issues consultant & 22 \\
\hline ICC & Informal care consultant & 40 \\
\hline GS & Geriatric specialist & 16 \\
\hline GP1 & General practitioner & 26 \\
\hline GP2 & General practitioner & 28 \\
\hline NP & Nurse practitioner & 33 \\
\hline HCN1 & Home care nurse & 26 \\
\hline HCN2 & Home care nurse & 28 \\
\hline HCN3 & Home care nurse & 32 \\
\hline \multicolumn{3}{|l|}{ Research } \\
\hline R1 & Researcher & 35 \\
\hline R2 & Researcher & 25 \\
\hline R3 & Researcher & 49 \\
\hline R4 & Researcher & 36 \\
\hline
\end{tabular}

to the researchers when it suited the interviewees best. For some of them this meant that they called the researcher back on a later occasion because of a client emergency; for others it meant they were available after they got home from work. Although in qualitative research face-to-face interviews are often preferred, evidence is limited regarding the notion that telephone interviews elicit lower quality data [15]. However, because of the known issues regarding building rapport and responsiveness [16], additional care was given to starting with friendly rapport and providing continuous verbal acknowledgment tokens throughout the interview. The researcher who led the interview has extensive experience with qualitative interviews; however, because this was the first time that telephone interviews were used, these two issues were pretested to become accustomed.

After verbal consent, the interviews were digitally recorded and transcribed verbatim. All participants verbally approved the anonymous use of these transcripts for publications. After the interviews, the interviewees were rewarded with a gift certificate of 25 euros. The interviews were reviewed until no new themes emerged from the interviews. After 20 interviews, we added the geriatric specialist and nurse practitioner, as suggested by a researcher. Their addition eventually led to sufficient insight into the topics of interest from 10 professionally different viewpoints. Hereafter, no new participants were added. Ethical approval was obtained from the Social Sciences Ethics Committee of Wageningen UR.

For this study, an extended form of the Food Choice Process Model (FCPM) [17] was used as a tool to develop a semi-structured interview guide, as food behaviours heavily influence the problem of undernutrition. The FCPM broadly considers the range of factors involved in food behaviours. To achieve comprehensiveness in the current study, on the level of influences in the FCPM, we added two nutritional aspects that were lacking: intrinsic product properties and physiological signals, as described by Shepherd [18]. Hereafter, we developed questions that were broad enough to elicit general answers for each main topic, followed by relevant prompts based on the provided answer to elicit in-depth answers within that topic. For example, we asked about the role of nutrition and undernutrition in the daily lives of older adults, and in the professional life of the interviewees (awareness). Following our hypothesis, we inquired how older adults are monitored regarding undernutrition and whether awareness issues affect monitoring effectiveness (monitoring). Finally, we asked the professionals how undernutrition among older adults is currently being treated and whether the treatment is affected by awareness and monitoring (treatment). A simplified form of the complete interview guide is given in Table 2 .

\section{Data analysis}

The interview transcripts were coded using constant comparison and content analysis, facilitated by the qualitative analysis software MAXQDA, version 10 (VERBI Software, Berlin, 2010). Two researchers in-vivo coded the first three interviews together to reach clarity about how to code the interviews consistently. The two researchers then coded the remaining interviews separately. Hereafter, the researchers discussed any conflicting codes and ambiguous statements to come to an agreement about the final coding scheme. Then, the identified experiences were categorized into main themes. Finally, the possible relationships between these emerged main themes were depicted within an overarching conceptual model.

\section{Results}

The interviews resulted in six major themes relevant to the three topics of interest: undernutrition awareness, monitoring, and treatment (Table 3). 
Table 2 Global overview of main interview questions (follow-up questions not shown)

Topics and questions
Undernutrition awareness
What is the influence of previous eating habits and traditions on the
current eating habits of older adults?
How would you define adequate nutrition and undernutrition?
To what extent are you and [people of the same profession] engaged
in nutrition among older adults?
What role does undernutrition play in the daily lives of older adults?
To what extent are you and [people of the same profession] engaged
in undernutrition among older adults?
Undernutrition monitoring
How is the nutritional status of older adults currently being monitored?
To what extent is the monitoring of undernutrition effective?
What are risk groups for undernutrition among older adults?
Undernutrition treatment
How is undernutrition among older adults currently being treated?
To what extent is the current treatment of undernutrition effective?
What are your experiences with medical nutrition for older adults?
What are your experiences with home-delivered meals for older adults?
How should we communicate with older adults about undernutrition?

\section{Undernutrition awareness}

\section{Theme 1 Adverse changes in nutrition behaviour.}

Interviewees stated that the nutrition behaviour of many older adults changes negatively with ageing. A first example of a change as provided by the interviewed professionals is the reduced appetite of older adults:

Many don't feel any appetite or thirst anymore, but they are often not aware of that. Only when I ask them about it, they say: 'Oh, yes, that's true actually' [D2].

Table 3 Themes that emerged from the interviews, shown by corresponding topic of interest

\begin{tabular}{l} 
Topics and themes \\
\hline Undernutrition awareness \\
Theme 1 Adverse changes in nutrition behaviour \\
Theme 2 Limited undernutrition awareness \\
Undernutrition monitoring \\
Theme 3 Unclear monitoring responsibilities and procedures \\
Theme 4 Lack of awareness, time, and priority as monitoring barriers \\
Undernutrition treatment \\
Theme 5 Lack of treatment personalization and justification \\
Theme 6 Lack of timely treatment implementation and evaluation
\end{tabular}

A second adverse change in nutrition behaviour is that some older adults suffer from reduced food enjoyment. According to the dietitians and researchers, this is caused by a diminished sense of taste, due to either ageing or medication use. One meal service employee related the diminished sense of taste to complaints they received from clients:

When they get older, they taste less or differently. For example, sometimes we receive complaints from clients about specific meals that they have consumed for a long time without any problems. They ask why we changed the meal, although there hasn't been a single change in the recipe [MSE3].

Even when the third adverse change, reduced food intake, has resulted in a tangible indication such as weight loss, older adults do not recognize this:

When I tell them they have lost weight, they respond: 'Well that's strange because I still eat normally, like I always did'. Their idea of eating normally has changed because obviously they ate more when they were younger, but they really fail to see that [HCN3].

However, as mentioned by the interviewees, when older adults do recognize the consequences of their reduced food intake, they do not counteract this reduction because they believe that losing weight is typical for ageing:

They don't see that [weight loss] as a problem and simply accept it as part of getting older. Old age comes with its infirmities, as they say [R3].

The reduced food intake is often attributed to the types of meals that older adults consume. The hot meal, which traditionally consists of a meat, vegetable, and starch component, is commonly the first meal that slowly deteriorates. Interviewees provided two reasons for reduced hot meal intake: lack of a dinner companion and their own physical limitations regarding walking and standing:

What we often hear is that people say: 'I'm alone, so then I have to cook for only myself, and I just don't feel like it'. And there's also a large group of people who just aren't able to cook anymore. Because let's be honest: it's not just cooking the meal, but you have to do the shopping, and planning, and so on. It's a lot more than merely cooking [MSE1].

\section{Theme 2 Limited undernutrition awareness.}

The term undernutrition is often not known to many older adults, nor its characteristics and consequences. 
Older adults have difficulty recognizing the characteristics of undernutrition:

When you look at older adults who live at home, if they suffer from undernutrition, it's often from sarcopenia. Then, there isn't much different on the outside, but rather with the body composition. The muscle mass decreases and fat mass increases, which makes them less functional, which is also a form of undernutrition. I think it's exactly this form of undernutrition that they don't recognize or that they aren't familiar with $[D C]$.

According to the interviewees, even when older adults do notice their decreased appetite, food intake, or weight, they do not think about undernutrition. Some older adults even perceive weight loss as positive rather than alarming:

Many people were like, 'Me, malnourished? No, I'm not malnourished. Yes, I lost some weight, but that's not so bad'. Or 'Yes, I'm a bit lighter than I was before, but is that such a problem?' [R2].

Because of this attitude towards weight loss, in most cases older adults take no action to counter their state of malnourishment:

Nobody comes into my office to complain about losing weight, telling me how malnourished they are, so that's obviously a problem. And when heavy people are losing weight, they are actually happy because, to be honest, that's beneficial for many physical ailments. And you have to realize that we work with a 'squeak system' [complaint system]. If people have a complaint and squeak about it, we try to fix it [...]. So that 'squeak system' predominates, and because there is almost no screening, there is a problem with tackling malnourishment [GP2].

Lastly, as the characteristics of undernutrition are difficult for older adults to recognize, so are its consequences:

They don't see the direct consequences of it [undernutrition]. While they are probably a little more tired, and have a reduced appetite. It's difficult to convince them that the reason for this is because they eat too little or inadequately [R2].

It is clear, therefore, that according to the interviewees older adults are either not aware of the adverse changes in nutrition behaviour or perceive the noticed changes more positively than negatively, and that both situations cause older adults to refrain from counteracting the adverse changes. This can lead to a state of undernutrition, about which little is known and which is neither recognized nor acted upon by older adults.

\section{Undernutrition monitoring}

\section{Theme 3 Unclear monitoring responsibilities and procedures.}

The interviewees' experiences and views regarding monitoring responsibilities and procedures varied both between and within the different types of professionals. Table 4 depicts these diverse views, grouped into undernutrition monitoring responsibilities, procedures, and barriers. The barriers are described in Theme 4 .

As can be seen in Table 4, the interviewees pointed to three groups of professionals as being responsible for undernutrition monitoring: home care nurses, GPs, and nurse practitioners. The nurses themselves also stated that they have a responsibility in undernutrition monitoring. However, they prefer observational procedures rather than procedures that involve systematic screening:

Do you use a questionnaire in which you ask about older adults' appetite, whether they experience difficulties walking up and down a staircase... [Interviewer].

No. No, and I think that that would be going too far [HCN2].

For the home care nurses? [Interviewer]

Yes. I mean, if you ask someone if they can still go up and down a staircase, that could be related to their knees, or their lungs, and their diet. There are so many things going on there, that a questionnaire like that does not tell me more [HCN2].

Are home care nurses the designated professionals to monitor undernutrition then? [Interviewer]

Well yes, and we certainly keep an eye on nutritional status, but never with a checklist. If we ask them questions, then those questions are tailored to that person, what you see at that time [HCN2].

This is in contrast to the views of dietitians and researchers, who would like to see monitoring by nurses using general screening questionnaires, like the SNAQ ${ }^{65+}$ (Short Nutritional Assessment Questionnaire for 65+). The interviewed geriatric specialist mentioned being aware of some negative experiences of nurses with general questionnaires. For this reason, at the time of the interview, the geriatric specialist was developing a questionnaire that matches the nurses' way of working, asking more specifically about nutrition behaviours:

When GPs want to ask home care nurses to keep an eye on patients, the GPs really have to provide the most literal questions you can think of. So currently, 
Table 4 Experiences and views on undernutrition monitoring responsibilities, procedures, and barriers that emerged from the interviews

\begin{tabular}{|c|c|c|c|c|c|c|c|c|c|c|c|c|c|c|c|c|c|c|}
\hline \multirow[b]{2}{*}{ Monitoring responsibilities } & \multicolumn{6}{|c|}{ Nutrition } & \multicolumn{9}{|c|}{ Care } & \multicolumn{3}{|c|}{ Research } \\
\hline & $\overline{\mathrm{DC}}$ & D1 & D2 & D3 & D5 & MSE1 & $\overline{E C}$ & ICC & GS & GP1 & GP2 & $\mathrm{NP}$ & HCN1 & $\mathrm{HCN} 2$ & $\overline{\mathrm{HCN} 3}$ & $\overline{\mathrm{R} 1}$ & R2 & R3 \\
\hline Older adults themselves & & & & & & & & & & & $x$ & & & & & & $x$ & $x$ \\
\hline Informal caregiver & & & & $x$ & & $x$ & & $x$ & & & & & & & & & & \\
\hline General practitioner (GP) & $x$ & $x$ & $x$ & $x$ & & & & & $x$ & & & & & & & $x$ & $x$ & $x$ \\
\hline Home care nurse ( $\mathrm{HCN})$ & $x$ & & & $x$ & $x$ & & $x$ & $x$ & $x$ & $x$ & $x$ & $x$ & $x$ & $x$ & $x$ & $x$ & $x$ & $x$ \\
\hline Nurse practitioner & $x$ & & $x$ & & & & $x$ & & $x$ & & & $x$ & & & & $x$ & $x$ & \\
\hline Monitoring procedures & DC & D1 & D2 & D3 & D5 & MSE1 & EC & ICC & GS & GP1 & GP2 & NP & HCN1 & $\mathrm{HCN} 2$ & HCN3 & $\mathrm{R} 1$ & R2 & R3 \\
\hline Screening with questionnaire at general practice & & $x$ & $x$ & $x$ & & & & & & & & & & & & $x$ & & $x$ \\
\hline Screening with questionnaire by $\mathrm{HCN}$ & $x$ & & & $x$ & $x$ & & $x$ & & $x$ & $x$ & & $x$ & & & & $x$ & $x$ & $x$ \\
\hline Observation by the $\mathrm{HCN}$ & & & & & & & & & & & & & $x$ & $x$ & $x$ & & & \\
\hline Screening with questionnaire by nurse practitioner & & & & & & & & & $x$ & & & $x$ & & & & & & \\
\hline Monitoring barriers & DC & D1 & D2 & D3 & D5 & MSE1 & EC & ICC & GS & GP1 & GP2 & NP & HCN1 & HCN2 & HCN3 & $\mathrm{R} 1$ & R2 & R3 \\
\hline Lack of awareness older adults & $x$ & $x$ & $x$ & $x$ & $x$ & $x$ & $x$ & $x$ & $x$ & $x$ & $x$ & $x$ & $x$ & $x$ & & $x$ & $x$ & \\
\hline Lack of awareness GP & $x$ & $x$ & $x$ & $x$ & & & & & $x$ & $x$ & $x$ & & $x$ & & & $x$ & $x$ & $x$ \\
\hline Lack of awareness HCN & & & $x$ & & & & & & & & & & $x$ & & & & & \\
\hline Lack of time GP & & & & $x$ & & & & & $x$ & $x$ & $x$ & & & & & $x$ & $x$ & \\
\hline Lack of time HCN & & & & $x$ & $x$ & & $x$ & & $x$ & & & $x$ & $x$ & $x$ & $x$ & & & $x$ \\
\hline Low priority of nutrition GP & $x$ & $x$ & & & & & & & & $x$ & $x$ & & & & & $x$ & & \\
\hline Low priority of nutrition $\mathrm{HCN}$ & & & & $x$ & & & & & $x$ & & & $x$ & & & & & & $x$ \\
\hline
\end{tabular}

Note: The interviews with D4, MSE2, MSE3, and R4 did not result in answers relevant to undernutrition monitoring responsibilities, procedures, and barriers. $D C$ dietitians' coordinator, D dietitian, MSE meal service employee, EC elder-issues consultant, ICC informal care consultantm, GS geriatric specialist, GP general practitioner, NP nurse practitioner, $R$ researcher

we're developing checklists [...]: has the patient eaten today, did you find food in the garbage, did you find empty bottles, do you think the patient drinks enough water? That kind of questions. You have to approach these people [nurses] on their own level [GS].

In addition, the interviewed nurse practitioner mentioned a combination of methods: observation and the use of a general screening questionnaire:

Nutrition is always discussed, but that can vary from asking whether someone had breakfast in the morning, and discussing the whole day like that [...]. I also use the SNAQ $\left[^{65+}\right]$, so measuring the arm circumference, and how much weight someone has lost [...]. I look at what strikes me, for example, that people use very few dairy products, which is always a very big gap. They often eat too little, and many unhealthy things in between [NP].

General practitioners were also mentioned as having an undernutrition monitoring responsibility. The interviewed GPs, however, consider neither themselves nor their own professional group as the designated monitoring professionals. Reasons for this are provided in the barriers in Theme 4.

Lastly, some interviewees underlined that older adults themselves and their informal caregivers also form an important link in undernutrition monitoring. However, as mentioned in Theme 2, limited undernutrition awareness among older adults impedes their role in undernutrition monitoring.

\section{Theme 4 Lack of awareness, time, and priority as monitoring barriers.}

The interviewees provided seven barriers to undernutrition monitoring, shown in Table 4. These monitoring barriers are lack of undernutrition awareness among older adults, GPs, and home care nurses; lack of time among GPs and home care nurses; and low priority of nutrition among GPs and home care nurses.

The lack of undernutrition awareness among older adults, the first monitoring barrier, has already been described extensively in Themes 1 and 2. According to the interviewees, the lack of undernutrition awareness among GPs is another factor that directly hampers undernutrition monitoring: 
GPs are not concerned with undernutrition. That's a big problem [...]. They don't know anything about nutrition. They only recognize undernutrition in the emaciated patients, who anyone from a distance can see are malnourished [R1].

Although the problem starts with limited undernutrition awareness among GPs, it is worsened by their limited time and the low priority they give to nutritional topics:

Older people often experience multiple problems. They have swollen feet, they have blood in their stool, and they are short of breath. So these are actually common medical complaints that take so much time that the aspect of nutrition becomes underexposed [GP1].

Regarding the nurses, similar to the GPs, awareness, time, and priority constraints apply. As stated by the interviewees, although undernutrition is currently better known among home care nurses than it was some years ago, progress is still necessary. In addition, as home care nurses' main tasks are care-related, undernutrition still tends to be a side issue with low priority. This low priority is partly caused by the time limitations the nurses already experience regarding their core (care) tasks:

One client, who has now moved, ate better if you stayed with her, because then there was some socializing. In the meantime, she ate only a little, and then you could stimulate her to eat more. We paid attention to that [HCN3].

Did you have time for that? [Interviewer]

Well, that was difficult of course, because less and less is covered by the CIZ [Dutch care provision authority] anyway, so we have to be very creative with our time. That's because it's not seen as very important [HCN3].

Undernutrition? [Interviewer]

Well, perhaps undernutrition is, because you cannot avoid finding that important, but they don't

translate that to 15 or 30 minutes of mealtime tasks, as that's a whole different order [HCN3].

Lastly, several interviewees stated that nurse practitioners are likely to have time for undernutrition monitoring. Nurse practitioners make house calls too, but contrary to home care nurses, they do not have specific care tasks that need to be completed within a certain time. This relates back to Theme 3 , where the practice nurse was indicated as one of the designated professionals for undernutrition monitoring.

In summary, the statements on undernutrition monitoring responsibilities, procedures, and barriers reflect diverse views regarding both the responsible monitoring professionals and the preferred monitoring procedures. Although mainly the GPs and home care nurses are pointed to as playing a monitoring role, the stated awareness, time, and priority barriers indicated a discrepant view on undernutrition management.

\section{Undernutrition treatment}

\section{Theme 5 Lack of treatment personalization and justification.}

The patient's treatment compliance affects the effectiveness of any undernutrition treatment. As stated by the interviewees, treatment compliance in turn is affected by two issues: personalization and justification.

The interviewees mentioned that GPs tend to be quick to prescribe ONS, whereas other types of treatment that are closer and personalized to the daily nutrition behaviour of older adults are possibly more appropriate. This tendency to prescribe ONS by default sometimes applies to dietitians too, depending on their knowledge and experience:

There are just a lot of dietitians who have a certain routine for themselves and think that they know what's good. And just continue prescribing those oral nutritional supplements [R2].

According to the researchers and dietitians, the correct manner would be to assess the underlying causes of the undernutrition and look into the elderly client's options. This process of personalization is seen as being necessary regarding the appropriate type of treatment, such as tube feeding, ONS, dietary advice, and homedelivered meals:

In our approach, we very much try to focus on screening first, followed by diagnostics. So screening is very general, looking at unintentional weight loss, low BMI, and arm circumference. Then we really want to look further at the actual cause of undernutrition. And the cause of undernutrition then predicts the treatment options [R1].

In addition, to meet a patient's needs and preferences, the prescriber should optimally offer variety and choice within this type of treatment:

Something you often see is that there are many flavours that they don't like, but, if you look further, there will always be two or three flavours that are reasonable. That's my experience. You have to explain to people [patients] that it's a search, and motivate 
them to keep trying until they find the taste they do like. That they should not give up at the first taste [D4].

The second important factor in treatment compliance is the extent of justification of that treatment. The chance of compliance is stated to be lower when professionals provide no or limited explanation to the patient regarding the need of the treatment. Adequate justification, on the other hand, can improve compliance:

Really, the role of the dietitian is very important in this topic [treatment compliance]. Recently, a study was performed regarding compliance with ONS. Also about who uses them, and for how long. When the GP prescribes ONS and lets the pharmacy deliver four boxes of them to the house, it doesn't work. Then they drink one of them and then they say 'Oh, I don't want this, I'll just have yogurt'. But when a dietitian is involved and adequately explains how it works, and why ONS [in this case] are better than full-fat yoghurt, well, then it works better [R1].

\section{Theme 6 Lack of timely treatment implementation and evaluation.}

The effectiveness of undernutrition treatment is affected by the timely implementation and evaluation of the treatment. The interviewees stated that both are currently inadequately performed, mainly because of their underlying causes: inadequate monitoring and low compliance:

I would like to see it done differently, but I'm afraid we're quite often forced to use ONS to prevent clients from worsening. The moment that undernutrition is assessed is often too late, so people are already weakened and their food intake has become quite low, making it more difficult to get them back on their feet again, and, in those cases, a tool [ONS] is quite desirable [D5].

In other cases, even after a malnourishment diagnosis, a considerable amount of time passes before older adults receive the correct treatment. In addition, the progress of the treatment is often evaluated inadequately:

Oral nutritional supplements are given pretty quickly [after diagnosis]. That's not the case with tube feeding. I think that sometimes professionals wait too long with it, muddle along too [...]. We looked at the use of ONS in a study a year ago: what happens at home and how is the dietary guidance there? There we saw that ONS compliance was very low and that the main reason was that the people using them are not being guided [...]. Then you often see that the drinks are not used the way they should be used, and not in the correct amount and for correct the period of time. So you're actually missing out, because then your goal is not achieved. But that goal in turn is not evaluated either, because the people are no longer being guided by a dietitian [...]. Simply prescribing without guiding is much less effective $[D C]$.

In summary, the interviewees mentioned that adequate undernutrition treatment requires two factors for the desired treatment compliance: treatment personalization and justification. In addition, to be able to assess both this compliance and the general success of treatment, continuous treatment evaluation is said to be imperative. Lastly, a thorough undernutrition diagnosis and cause assessment is mentioned as being crucial for the timely implementation of the correct treatment.

The combined experiences of the participants within the described six themes can be illustrated with a conceptual model regarding undernutrition awareness, monitoring, and treatment, shown in Fig. 1. This model shows the overarching association of limited undernutrition awareness with monitoring and treatment. Moreover, it depicts the impeding factors of the latter two matters. These nine impeding factors are described extensively within the last four themes that emerged from the interviews.

\section{Discussion}

This is the first study to assess qualitatively the experiences of Dutch nutrition and care professionals and researchers with undernutrition awareness, monitoring, and treatment among older adults. We considered such

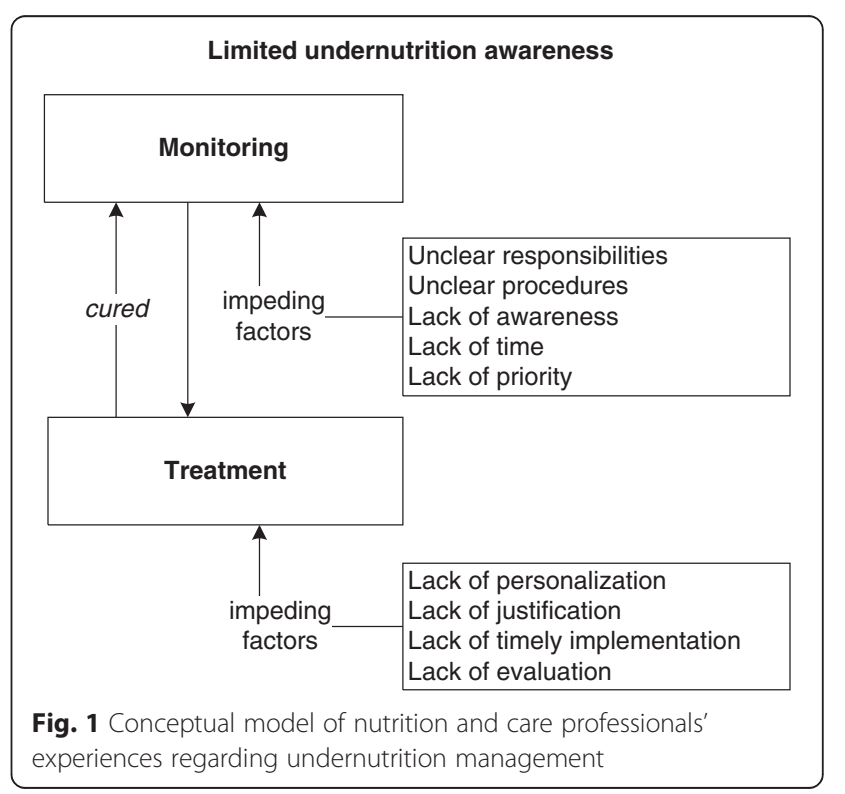


a study to be necessary because of current undernutrition management difficulties [9]. Moreover, because such difficulties are not confined to the Netherlands, studies that resembled ours were conducted in Australia [10, 19, 20], Canada [11], and the UK [21], with in general similar results.

As hypothesised, the relationships between the different topics and themes as shown in Fig. 1 indicate that limited undernutrition awareness negatively affects the aspects of monitoring and treatment. Despite recent efforts in practice, more awareness is still necessary to achieve adequate undernutrition management. According to the interviewees, limited awareness causes older adults to refrain from counteracting the adverse nutrition changes that are often associated with ageing. Furthermore, there seems to be ambiguity about which professionals are responsible for monitoring and which monitoring procedures are preferred. In addition, the experiences indicate that lack of awareness, time, and priority are monitoring barriers. Lastly, they indicate that the currently inadequate treatment personalization, justification, implementation, and evaluation negatively influence undernutrition management.

Limited awareness among older adults appears to be an important impeding factor for undernutrition management. According to the professionals, if the older adults themselves take no action, it becomes less likely that potentially needed interventions will be applied in the first place, let alone in a timely manner. This puts the burden of undernutrition monitoring in almost its entirety on the primary care professionals and informal caregivers around the older adults. However, as pointed out by many interviewees, undernutrition awareness among primary care professionals also leaves much to be desired. Although not specifically focused on undernutrition, other nutrition-related studies reveal similar findings among primary care professionals $[11,19,20]$. Fortunately, these awareness issues are gradually being acknowledged, as efforts are being put into facilitating adequate undernutrition management in the home care setting [9, 22]. Still, it would be helpful to make an early start with increasing awareness about adequate nutrition among older adults, preferably even before already suffering from many risk factors. This need for more nutrition education among older adults is also recommended in a review, in which it is proposed that older adults can change their eating habits when sufficiently supported [23].

Our results indicate that GPs, nurse practitioners, and home care nurses need to pay more attention to undernutrition monitoring, as they are the first and most accessible health professionals for older adults. However, the GPs in our study stressed that they lack both the time and the expertise to monitor undernutrition among their patients, deeming themselves incapable of doing so. These experiences are similar to those of GPs and nurse practitioners in a recent Australian study [10], and of community nurses in a study in the UK [21]. On the other hand, the home care nurses stated that they should monitor for undernutrition, but they too lack the time as the more severe and acute problems take priority. Finally, nurse practitioners are suggested as being the most suitable professionals to take on undernutrition monitoring, as they are able to make more time available for undernutrition monitoring than either GPs or home care nurses. Previous Dutch research, although more in relation to obesity, indicates the involvement of practice nurses in nutrition [24]. However, since nurse practitioners have many responsibilities too, there is still no consensus among the interviewees about the most suitable group of professionals for undernutrition monitoring. Nonetheless, the current Dutch guidelines for undernutrition management advocate that primary care professionals should monitor older adults and refer at-risk older adults to a dietitian for further treatment. Moreover, as self-management gains popularity in our society, other solutions that require more involvement of older adults and their informal caregivers can be found in the current trend of using telehealth and e-health approaches to improve health [25].

According to the Dutch undernutrition guidelines and as stated by the interviewees, adequate undernutrition treatment is only likely when preceded by a full undernutrition diagnosis and cause assessment. This facilitates personalization and justification of the treatment towards the older adults. In severe cases, this treatment cannot be limited to the mere promotion of food consumption, and other approaches are necessary. As compliance with ONS, which in practice are often the first choice, can be low in community-dwelling older adults, dietitians should try to find the most suitable treatment or type of supplement and above all, explain its necessity [26]. Innovative nutritional concepts that are closer to common nutritional habits of older adults could provide an appropriate treatment. Nonetheless, regardless of the type of treatment, successful undernutrition treatment requires the setting of personalized targets for older adults regarding their treatment and the continuous evaluation of their progress.

This study purposively selected a variety of professionals and researchers and succeeded in recruiting 22 participants. It should be noted that the purposively selected experts represent only a selection of all possible nutrition and care professionals who are involved in undernutrition management. For instance, treatment of undernutrition can also connote the involvement of 
dentists, psychologists, and physical therapists. However, our study intended to provide an explorative impression of the experiences of a varied, but not complete, collection of professionals and researchers. Still, it should be also noted that the interviewees presumably assign more importance to undernutrition management than random professionals from the same profession.

\section{Conclusions and implications}

The experts' experiences imply that undernutrition awareness is limited, both among older adults and among care professionals. As supported by other studies, more nutrition education can counteract this limited awareness. In addition, it seems unclear to the interviewees who exactly are responsible for undernutrition monitoring and how this monitoring should be carried out. Whereas the care-oriented interviewees feel that they have few nutritional responsibilities, the Dutch guidelines propose that home care nurses play a large role in the monitoring. Although it is already valuable that, contrary to many other countries, the Netherlands have undernutrition management guidelines, attracting more attention to these guidelines can counteract this ambiguity. Improved monitoring can support the dietitians, who currently feel that they become involved too late, leading to decreased treatment effectiveness. In turn, treatment effectiveness would benefit greatly from dietitians who train in following the guidelines on undernutrition treatment, with specific attention to personalization, justification, implementation, and evaluation. In general, the interviewees desire a coherent and feasible allocation of responsibilities regarding undernutrition monitoring and treatment. This implies that the available guidelines on undernutrition management require more attention and facilitation.

\section{Competing interests}

The authors declare that they have no competing interests.

\section{Authors' contributions}

$C Z$ and EvD developed the interview guide, conducted the interviews, and analysed the data. CZ wrote the manuscript. AHN, SK, and LdG reviewed the interview guide and the manuscript, and provided research guidance. All authors read and approved the final manuscript.

\footnotetext{
Acknowledgements

The authors gratefully acknowledge the financial support from the Wageningen UR IPOP Customized Nutrition programme financed by Wageningen UR, the Dutch Ministry of Economic Affairs, Agriculture \& Innovation, and the graduate school VLAG. The authors would like to thank all interviewees for their time and involvement, and Catherine O'Dea for her professional work as language editor.
}

Received: 22 July 2015 Accepted: 18 November 2015

Published online: 24 November 2015

\section{References}

1. Sharkey JR, Branch LG, Zohoori N, Giuliani C, Busby-Whitehead J, Haines PS. Inadequate nutrient intakes among homebound elderly and their correlation with individual characteristics and health-related factors. Am J Clin Nutr. 2002;76:1435-45.

2. Chen $\mathrm{CCH}$, Bai YY, Huang GH, Tang ST. Revisiting the concept of malnutrition in older people. J Clin Nurs. 2007;16:2015-26.

3. Ritchie CS, Burgio KL, Locher JL, Cornwell A, Thomas D, Hardin M, et al. Nutritional status of urban homebound older adults. Am J Clin Nutr. 1997;66:815-8.

4. Chapman IM, MacIntosh CG, Morley JE, Horowitz M. The anorexia of ageing. Biogerontology. 2002;3:67-71.

5. Schilp J, Wijnhoven HA, Deeg DJH, Visser M. Early determinants for the development of undernutrition in an older general population: Longitudinal Aging Study Amsterdam. Br J Nutr. 2011;106:708-17.

6. Sharkey J, Johnson CM, Dean WR. Physical limitations in meal preparation and consumption are associated with lower musculoskeletal nutrient (calcium, vitamin D, magnesium, and phosphorus) intakes in homebound older adults. J Nutr Health Aging. 2012;16:675-7.

7. Schilp J, Kruizenga HM, Wijnhoven HA, Leistra E, Evers AM, van Binsbergen JJ, et al. High prevalence of undernutrition in Dutch community-dwelling older individuals. Nutrition. 2012;28:1151-6.

8. Dutch Malnutrition Steering Group. Guideline Screening and treatment of malnutrition. Amsterdam: Dutch Malnutrition Steering Group; 2011.

9. Van Koningsbruggen W. Ondervoeding: waar valt nog winst te behalen? [Malnutrition: where is still room for improvement?]. Ned Tijdschr voor Voeding Diëtetiek. 2014;68:22-4.

10. Hamirudin AH, Charlton K, Walton K, Bonney A, Albert G, Hodgkins A, et al "We are all time poor" - is routine nutrition screening of older patients feasible? Aust Fam Physician. 2013;42:321-6.

11. Wynn K, Trudeau JD, Taunton K, Gowans M, Scott I, Graddipclinepi M, et al. Nutrition in primary care Current practices, attitudes, and barriers. Can Fam Physician. 2010;56:E109-16.

12. Corbin JM, Strauss A. Grounded theory research: Procedures, canons, and evaluative criteria. Qual Sociol. 1990;13:3-21.

13. Kondracki NL, Wellman NS, Amundson DR. Content analysis: review of methods and their applications in nutrition education. J Nutr Educ Behav. 2002;34:224-30.

14. Gillham B. Research Interviewing: The Range of Techniques. Maidenhead: Open University Press; 2005.

15. Novick G. Is there a bias against telephone interviews in qualitative research? Res Nurs Health. 2008;31:391-8.

16. Irvine A, Drew P, Sainsbury R. "Am I not answering your questions properly?" Clarification, adequacy and responsiveness in semi-structured telephone and face-to-face interviews. Qual Res. 2012;13:87-106.

17. Sobal J, Bisogni CA. Constructing food choice decisions. Ann Behav Med. 2009;38 Suppl 1:S37-46.

18. Shepherd R. Factors influencing food preferences and choice. In: Shepherd R, editor. Handb. Psychophysiol. Hum. Eat. 1st ed. New York: John Wiley \& Sons Ltd.; 1989. p. 3-24.

19. Ball L, Hughes R, Leveritt M. Health professionals' views of the effectiveness of nutrition care in general practice setting. Nutr Diet. 2013;70:35-41.

20. Ashby S, James C, Plotnikoff R, Collins C, Guest M, Kable A, et al. Survey of Australian practitioners' provision of healthy lifestyle advice to clients who are obese. Nurs Health Sci. 2012;14:189-96.

21. Green SM, James EP, Latter S, Sutcliffe M, Fader MJ. Barriers and facilitators to screening for malnutrition by community nurses: a qualitative study. J Hum Nutr Diet. 2014;27:88-95.

22. Tweede Kamer Der Staten-Generaal. Vaststelling van de begrotingsstaten van het Ministerie van Volksgezondheid, Welzijn en Sport (XVI) voor het jaar 2015; Amendement [Determination of the budget of the Ministry of Health, Welfare and Sport (XVI) for the year 2015; Amendment]. 2014. Available from: http://www.tweedekamer.nl/ kamerstukken/amendementen/detail?id=2014Z21170\&did=2014D42769. Accessed: 30-11-2014.

23. Keller $\mathrm{HH}$. Promoting food intake in older adults living in the community: a review. Appl Physiol Nutr Metab. 2007;32:991-1000.

24. Van Dillen SME, Noordman J, van Dulmen S, Hiddink GJ. Examining the content of weight, nutrition and physical activity advices provided by Dutch practice nurses in primary care: analysis of videotaped consultations. Eur J Clin Nutr. 2014;68:50-6. Nature Publishing Group. 
25. Inglis SC, Clark RA, MCAlister FA, Ball J, Lewinter C, Cullington D, et al. Structured telephone support or telemonitoring programmes for patients with chronic heart failure. Cochrane Database Syst Rev. 2010;4(8):CD007228.

26. Milne AC, Potter J, Vivanti A, Avenell A. Protein and energy supplementation in elderly people at risk from malnutrition. Cochrane Database Syst Rev. 2009;15(2):CD003288.

Submit your next manuscript to BioMed Central and we will help you at every step:

- We accept pre-submission inquiries

- Our selector tool helps you to find the most relevant journal

- We provide round the clock customer support

- Convenient online submission

- Thorough peer review

- Inclusion in PubMed and all major indexing services

- Maximum visibility for your research 